\title{
Systematic mapping study of economic and business models of cloud services
}

\author{
Isaac Odun-Ayo ${ }^{1}$, Toro-Abasi Williams ${ }^{2}$, Olusola Abayomi-Alli ${ }^{3}$, Jamaiah Yahaya ${ }^{4}$ \\ ${ }^{1,2}$ Department of Computer and Information Sciences, Covenant University, Nigeria \\ ${ }^{3}$ Department of Electrical and Information Engineering, Covenant University, Nigeria \\ ${ }^{4}$ Faculty of Information Science and Technology, Universiti Kebangsaan Malaysia, Malaysia
}

\begin{tabular}{l}
\hline Article Info \\
\hline Article history: \\
Received Aug 25, 2019 \\
Revised Oct 27, 2019 \\
Accepted Nov 11, 2019 \\
\hline
\end{tabular}

\section{Keywords:}

Cloud business models

Cloud computing

Cloud economics models

Cloud services

Systematic mapping

\begin{abstract}
Cloud computing is a business paradigm wherein computers and computing related services are provided by Cloud Service Providers to consumers either as software, development platform, or infrastructure. From an economic and business perspective, Cloud services involve cost, ownership quality of service and service level agreements. There are studies on economic and business models of cloud services on the cloud landscape especially in the area of pricing. Despite this, there is still a dearth of papers in this area of study. The objective of this study is to conduct a systematic mapping study to collect all relevant research on economic and business models of Cloud services. A systematic map provides a structured overview in a particular research area. The representation of the mapping process offers unique course-grained overview of the results. The results are presented in terms of research such as evaluation and solution, and contribution such as tools and method utilized. The results showed that there are more publications on pricing models in relation to tools with $6.87 \%$ and model with $14.5 \%$, more publications on economic and business implications in terms of method with $11.45 \%$, more publications on Cloud market in term of processes with $6.87 \%$, more papers on security in the area of evaluation with $8.55 \%$ and validation research with $6.58 \%$, and more papers on Cloud markets with respect to experience with $4.61 \%$ and validation with $5.92 \%$. The research gaps identified in this study should motivate researchers to carry out more mapping studies in the field.
\end{abstract}

Copyright $@ 2020$ Institute of Advanced Engineering and Science. All rights reserved.

\section{Corresponding Author:}

Isaac Odun-Ayo,

Department of Computer and Information Sciences,

Covenant University, Ota, Nigeria.

Email: isaac.odun-ayo@ covenantuniversity.edu.ng

\section{INTRODUCTION}

The Cloud computing model is one that enables pervasive on-demand access to interconnected pools of computing resources (physical or virtualized), which are presented to users as a single computing resource based on pre-agreed service levels between the Cloud Service Providers (CSPs) and the Cloud customers [1]. Cloud computing is a business involving its own economics, hence the issue of perceived quality of service (QoS) becomes relevant. Service level agreements are imperative as they allow customers benchmark CSPs' service performance against expectations and promises. Cloud computing offers several services in a virtualized format to customers through the internet [2]. It has three primary Cloud services which are Platformas-a-Service (PaaS), Infrastructure-as-a-Service (IaaS) and Software-as-a-Service (SaaS). Beyond these models, there are additional models such as those relating to buildings and customer management, development of Clouds services, as well as migrating services to and across Cloud. These models are specifically essential to the CSPs. Despite the fact that the CSP's are making effort to offer excellent cloud services, issues of trust management still exist [3]. In addition, cloud computing is very broad and there are a plethora of subjects such 
as management optimization and identity management requiring significant discussion $[4,5]$. Such issues are directly or indirectly related to the focus of this study.

For any viable business, economic models help in formulating pricing models to maximize return on invested capital, increase customer base as well as efficiently manage resources utilization [6]. The CSPs in turn utilize various pricing strategies such as paying for limitless usages, pay-per-use; fixed pricing, pay for resources and recurrent subscription [7]. From the customer's perspective, there are models that are suited to business. One such is Cloud accounting, which is usually provided as a service and not as a product and enables customers to access accounting data via the Internet [8]. This is a model in itself, because the customers purchase the "use" of accounting software from specialized CSPs and not the software itself. These pricing models all have their advantages and draw backs and have been discussed in [8]. The main purpose of a business model is to clearly identify rivals; identify weaknesses and systematically evaluate new opportunities and business ideas, identify and leverage on own strengths which can tremendously improve success probabilities [9]. In addition, IaaS offers different types of virtual machines with different price regimes. A decision assisted system is available for computing cost and decision strategies for selecting suitable IaaS providers, aimed at having reasonable amount of customers if quality of service is provided at reasonable cost [10]. One of the services provided by the CSP is internet bandwidth, hence pricing becomes paramount. By using consumption data of internet bandwidth, it is possible to optimize the use of bandwidth using the mixed integer linear programming model [11]. Also, the digital traction metrics using net promoter score helps to determine the customer involvement in comparison to traditional methods used in busines [12]. This enhances customer satisfaction evaluation and promoting business for the CSP. Certainly, the topic of economic and business models of Clouds services is an interesting one that is worth researching on. Research has been carried out in the past on this topic but most of these studies are skewed towards certain directions and do not cover the concept in its entirety.

The systematic mapping process is usually done in facets to allow for consideration of all aspects. Three aspects were employed in this research namely; the topic, contribution and research facets. The topic facet was used to extract core aspects of Cloud economics and business models. The research facet focused on the type of research, while the contribution facet involved method and model applied. The motivation for this work is that more researches are still required in the areas of economic and business models of cloud services. Hence, the problem this study seeks to address is identifying areas where there are dearth of papers and pointing it out to upcoming researchers. The main purpose of this paper therefore, is to conduct a systematic mapping study of economic and business models of Cloud services. The major contribution of this review is that a visual map was created with percentages indicating the extent of work that has been done in various research types and research contributions such as framework and model in this field of study. The rest of this paper is organized as follows: an examination of related work is in Section 2, a discussion of the materials and methods is done in Section 3. Section 4 presents the results and discussion. Section 5 concludes the paper and recommends further studies.

\section{RELATED WORK}

The work in [13] provides direction on how interested reasechers should conduct a systematic study. It provided guidelines to enhance the study, citing advantages and disadvantages in comparison to a systematic literature review. In the affirmative, the authors provided a step-by-step approach to producing a systematic map. In the study [14] the authors identified the software patterns present in software development projects with respect to requirement engineering, and provides a sound understanding of the process based on the patterns and parameters used.

Study on programming models and policy languages on the cloud, using the guidelines in $[13,15]$. This research used six classes of study in the areas of survey, framework, privacy, paradigms, accountability and reliability, and security in relation to the focus of study. [16] conducted a study of domain-specific languages with a view to identifying gaps in the field. The study focused on palnning, conducting and reporting reviews as guidelines covering the period 2003 to 2014. The study in [17] carried out a systematic mapping study to find primary studies which addressed game-based learning methods used in software engineering education. [18] is cloud design and deployment models: a systematic mapping study. The classification scheme in relation to design and deployment models discussed six topics which are design, service deployment. implementation, configuration, privacy and security. The work of [19] is a study in cloud-based testing of sofware which alsohad a unique classification scheme.Testing method such the non-functional and functional approaches were examined show peculiar natture of the methods. The paper used 69 studies from 75 discovered publications. The studies was used for to provide quantitative results based on sound analysis. A singular experiment was utilized fro the evaluation and the eventual soltions provided. [20] is a systematic mapping study on cloud-based mobile application testing. The procedure on cloud-based testing discussed four topics 
which are security testing, compatibility testing, functional testing and GUI testing. The contribution facet for the studies focused on framework, metric, tool, method, and model. [21] discussed the lessons learned based on a review process within in the domain of software engineering. It was a summary of review, which examined a number of reviews being undertaken by the authors and others and proffered some lessons on applicability of this to software engineering practice. [22] assesses the relevance of systematic review using evidence-based software engineering methods for aggregating results. The authors used a manual search of some journals and conference proceedings.

The work in [23] is a systematic mapping study of of software quality measurement: research trends, model and method. The paper discussed software quality model, empirical and analytical methods. The paper focused on population, intervention, comparison and outcome. The paper discussed the implementation of software quality model in terms of ISO/IEC 9126 and ISO/IECSQuaRE. It concluded the ISO SQuaRE is most utilized. The work in [24] is service request scheduling based on quantification principle using conjoint analysis and $\mathrm{z}$-score in the cloud. The study identified the most preferred attribute of a server and method to determine allocation of server. The paper also discuss a scheduling principle that prioritizes the request based on services required. The research enhancing provisioning in the area of business model in IaaS for the CSP. The work in [25] is resource allocation in cloud computing using advanced imperialist competitive algorithm. The work focused on providing an efficient algorithm for resources allocation to satisfy the cloud providers and customers. This examined a combinatorial approach to improve resource allocation by combining the Tabu Search Algorithm with ICA-based method to achieve an optimal solution at an acceptable time. The proposed method offer better performance in terms of cost. From literature examined, there has been no work focused specifically on systematic mapping study of economic and business models of cloud services.

\section{RESEARCH METHOD}

\subsection{Definition of Research Questions (Research Scope)}

The guidelines in $[13,22]$ was used for carrying out the systematic study for this paper. The systematic mapping process is used to develop a classification scheme and the steps as as shown in Figure 1. A systematic mapping study provides an overview of a research area in order to find out research gaps on a particular topic in order to provide areas for future research areas [26]. The definition of research questions is the first step in accomplishing successful reviews and herein the scope of the entire study is outlined. A search is conducted for primary studies in the proposed study field. The papers found are then filtered to determine their relevance to the study. The next step is the key wording process. It involves using the abstracts of the paper to design a procedure. The last step is the process of data extraction, which takes place with a view to a systematic map being created. The outcome at every stage serves as input to the next stage and creates the mapping

With respect to the title of this paper and in order to meet the objectives as well as answer the research questions, a total of 152 papers were deemed relevant out of an initial set comprising 1215 papers. The period covered in the resaerch was $2009-2018$.

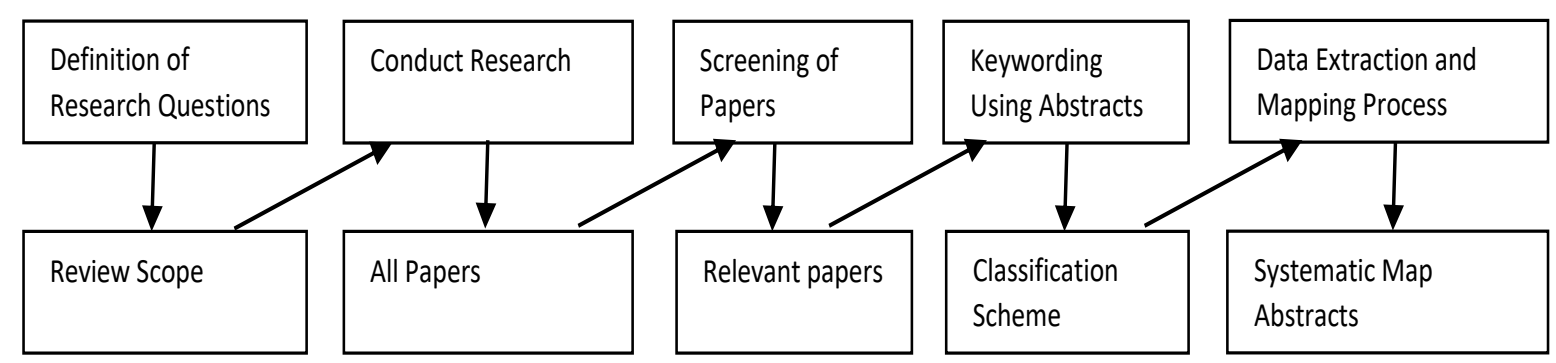

Figure 1. The systematic mapping process [13]

\subsection{Definition of Research Questions}

An appropriate research question was essential for a comprehensive study, because systematic maps can be broad and generally used to get an insight into the quality and types of research activities that have been done in any given field of study. Hence, research questions were necessary to narrow the focus. In this particular study, they are defined below:

a) RQ1: When and where have studies in economic and business models of Cloud Services been published?

b) RQ2: Which subareas have economic and business models of Cloud Services been presented?

c) RQ3 What research approaches do these studies apply and what contributions were enunciated? 


\subsection{Conduct Search for Primary Studies (All Papers)}

Literature review is only possible when there are materials to examine, hence a search for primary studies was imperative in this study. The primary search focused on searching relevant literature from online database resources using the search string. Thereafter, a backward snowballing was carried out to complement the search process [27]. Typically, searching for papers usually involves exploring major electronic databases. However, it is possible to accomplish this by manually searching through books, printed materials, conference proceedings and journals. The focus of the search only included high quality papers which were published in journals, symposiums, conferences and books. The IEEE, Springer, Science Direct, ACM and Scopus digital libraries were queried using a search string defined as follows:

\section{(TITLE (“Economic Models”) OR KEY (“Economic Models") OR KEY (“Business Models”)) AND (TITLE Cloud Services)).}

The searches on the electronic databases were performed by running search string on documents' meta data. This ensured that relevant publications were not omitted. All results relating to cloud and computer science in the databases selected were also considered.

\section{RESULTS AND DISCUSSION}

The analysis focused on identifying number of publications in each of the categories to visualize at a glance which categories had received greater emphasis in past research works. This in essence helps identify existing gaps in literature. The scope of this work is the mapping Cloud busines and economic models and this served as the metric used for analysis. The following subsections discuss the result of the study.

\subsection{Topic Category and Contribution Facet}

The contribution facet focus on discussion in the areas of framework, model, tool, evaluation, metric, method [20]. The extracted topics by the classification scheme of economics and business models of Cloud services are: security, pricing models, economic and business implication, cloud markets, business platforms and frameworks and cloud SME. At Table 1 is the content of contributions and topics. Figure 2 shows the percentage of topics on contribution category. Figure 4 depicts the systematic map of economics and business models of Cloud services. The left half of Figure 4 shows results of the contribution facet. This category depicts the contributions to a study. The result indicates that $32.82 \%$ of the 152 publications discussed model. $2.29 \%$ of the analyzed publications focused on metric, while $21.37 \%$ discussed economic and business tools. Finally, $27.48 \%$ and $16.03 \%$ respectively dwelt on method and process relating to the subject matter.

From Figure 4, model discussion contributed $32.82 \%$ of all the papers reviewed. Of this $32.82 \%$, $10.69 \%$ were security related, $14.5 \%$ on pricing models, $3.82 \%$ on Cloud markets, $3.05 \%$ on business platforms and frameworks and the final $0.76 \%$ on Cloud SME.

Table 1. Contribution and Topics Primary Studies

\begin{tabular}{|c|c|c|c|c|c|}
\hline Facet & Metric & Tool & Model & Method & Process \\
\hline $\begin{array}{l}\text { Topic } \\
\text { Security }\end{array}$ & & $\begin{array}{l}6,10,24,37 \\
44,47,132\end{array}$ & $\begin{array}{l}1,4,8,21,38,40,56,83, \\
87,90,97,149,136,150\end{array}$ & $\begin{array}{l}9,22,26,35,41, \\
52 .\end{array}$ & $16,25,29,30,94$ \\
\hline Pricing Models & & $\begin{array}{l}11,43,45,57 \\
100,112,119, \\
152,143,\end{array}$ & $\begin{array}{l}2,3,14,19,20,27,32,55, \\
60,62,63,66,80,115,116, \\
123,131,133,134\end{array}$ & $\begin{array}{l}72,78,117,121 \\
125,138,146,147\end{array}$ & \\
\hline $\begin{array}{l}\text { Economic and } \\
\text { Business } \\
\text { Implications }\end{array}$ & & & & $\begin{array}{l}12,17,18,28,42,51, \\
54,70,95,106,109, \\
111,114,130,151\end{array}$ & $7,13,23,139$ \\
\hline Cloud Markets & 15,144, & $33,34,46$ & $36,39,61,75,113$ & 49 & $\begin{array}{l}48,50,58,64,73 \\
84,120,145,148\end{array}$ \\
\hline $\begin{array}{l}\text { Business } \\
\text { Platforms and } \\
\text { frameworks }\end{array}$ & & $\begin{array}{l}53,65,68,69 \\
82,85\end{array}$ & $59,67,71,79$ & $\begin{array}{l}76,77,91,102, \\
108,128\end{array}$ & $104,129,141$ \\
\hline CloudSME & 135 & $107,124,142$ & 74 & & \\
\hline Percentage & $2.29 \%$ & $21.37 \%$ & $32.82 \%$ & $27.48 \%$ & $16.03 \%$ \\
\hline
\end{tabular}




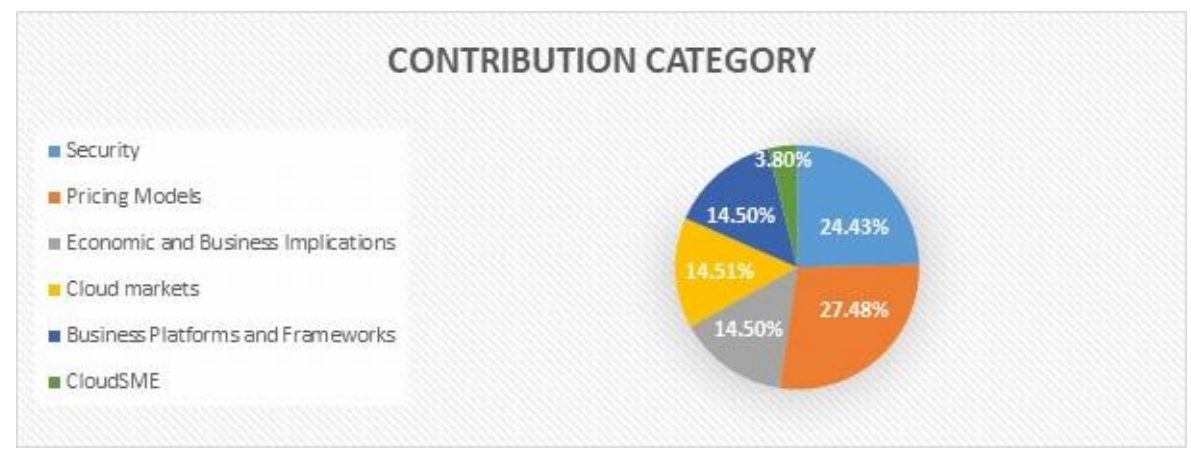

Figure 2. Percentage of topics on contribution category

\subsection{Topic Facet and Research Category}

The categories and description of research works which include evaluation research, experience paper, opinion paper, philosophical papers, solution proposals and validation research as discussed in [28] was utilized. At Table 2 is the content of topic and research considerations. Figure 3 shows the percentage of topics on research category. Depicted on the right half on Figure 4 are the results of the type of researches conducted in the focus of study. The results showed that $29.61 \%$ of the surveyed papers proposed solution, while $28.29 \%$, were evaluation based publications. $21.71 \%$ were validation based, $7.89 \%$ were philosophical and $12.5 \%$ were experience papers. The right half of Figure 2 depicts the relationship between the topic and the research facet. Solution proposal contributed $29.61 \%$ of the papers reviewed in terms of type of research. Out of this $29.61 \%$, $5.26 \%$ were on security, $3.95 \%$ were on pricing models, $4.61 \%$ were on economic and business implications, $1.97 \%$ were on Cloud markets, $5.92 \%$ were on business platform and frameworks and $7.89 \%$ were on Cloud SME.

Table 2. Research and Topic Facet Primary Studies

\begin{tabular}{|c|c|c|c|c|c|c|}
\hline $\begin{array}{l}\text { Research } \\
\text { Facet } \\
\text { Topic }\end{array}$ & Evaluation & Validation & Solution & Philosophical & Experience & Opinion \\
\hline Security & $\begin{array}{l}1,4,8,9,22,26,30 \\
31,38,40,44,47,132\end{array}$ & $\begin{array}{l}6,10,16,25,29,35,41 \\
52,94,97\end{array}$ & $21,24,37,56,83,87,90,14 !$ & & 136,150 & \\
\hline Pricing Models & $\begin{array}{l}2,3,14,19,27,32,43 \\
115,123\end{array}$ & $\begin{array}{l}11,20,60,66,100, \\
131\end{array}$ & $55,62,63,133,134,152$ & 80 & 116 & \\
\hline $\begin{array}{l}\text { Economic and } \\
\text { Business } \\
\text { Implications }\end{array}$ & $\begin{array}{l}12,28,42,54,70,109 \\
151\end{array}$ & 18,130 & $7,13,23,95,106,111,114$ & 17,51 & 139 & \\
\hline Cloud Markets & $15,33,34,36,143,144$ & $\begin{array}{l}46,48,57,61,119 \\
120,112,117,147\end{array}$ & $39,75,113$ & $\begin{array}{l}49,50,64,73 \\
84,138\end{array}$ & $\begin{array}{l}45,72,58,78 \\
121,145,148\end{array}$ & \\
\hline $\begin{array}{l}\text { Business } \\
\text { Platforms and } \\
\text { frameworks }\end{array}$ & $53,65,79$ & $102,108,125,128$ & $\begin{array}{l}59,67,68,69,76,77,82,85 \\
146\end{array}$ & 122 & $\begin{array}{l}71,91,104,129 \\
141\end{array}$ & \\
\hline CloudSME & $5,86,92,124,135$ & 107,142 & $\begin{array}{l}74,88,89,96,99,101,103 \\
105,110,127,126,140,\end{array}$ & 118,137 & $81,93,98$ & \\
\hline Percentage & $28.29 \%$ & $21.71 \%$ & 29.61 & $7.89 \%$ & $12.50 \%$ & $0 \%$ \\
\hline
\end{tabular}

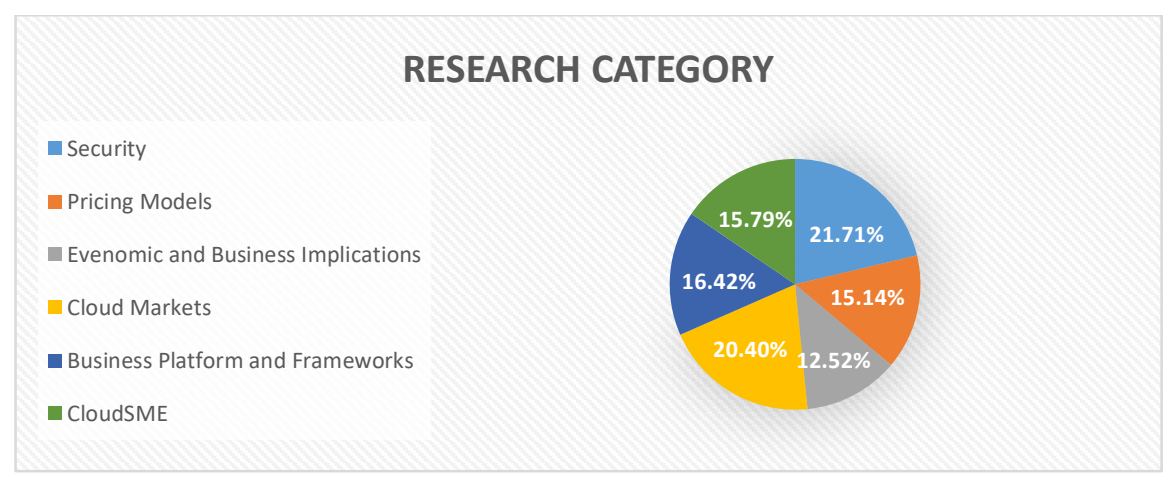

Figure 3. Topics percentage on research category 


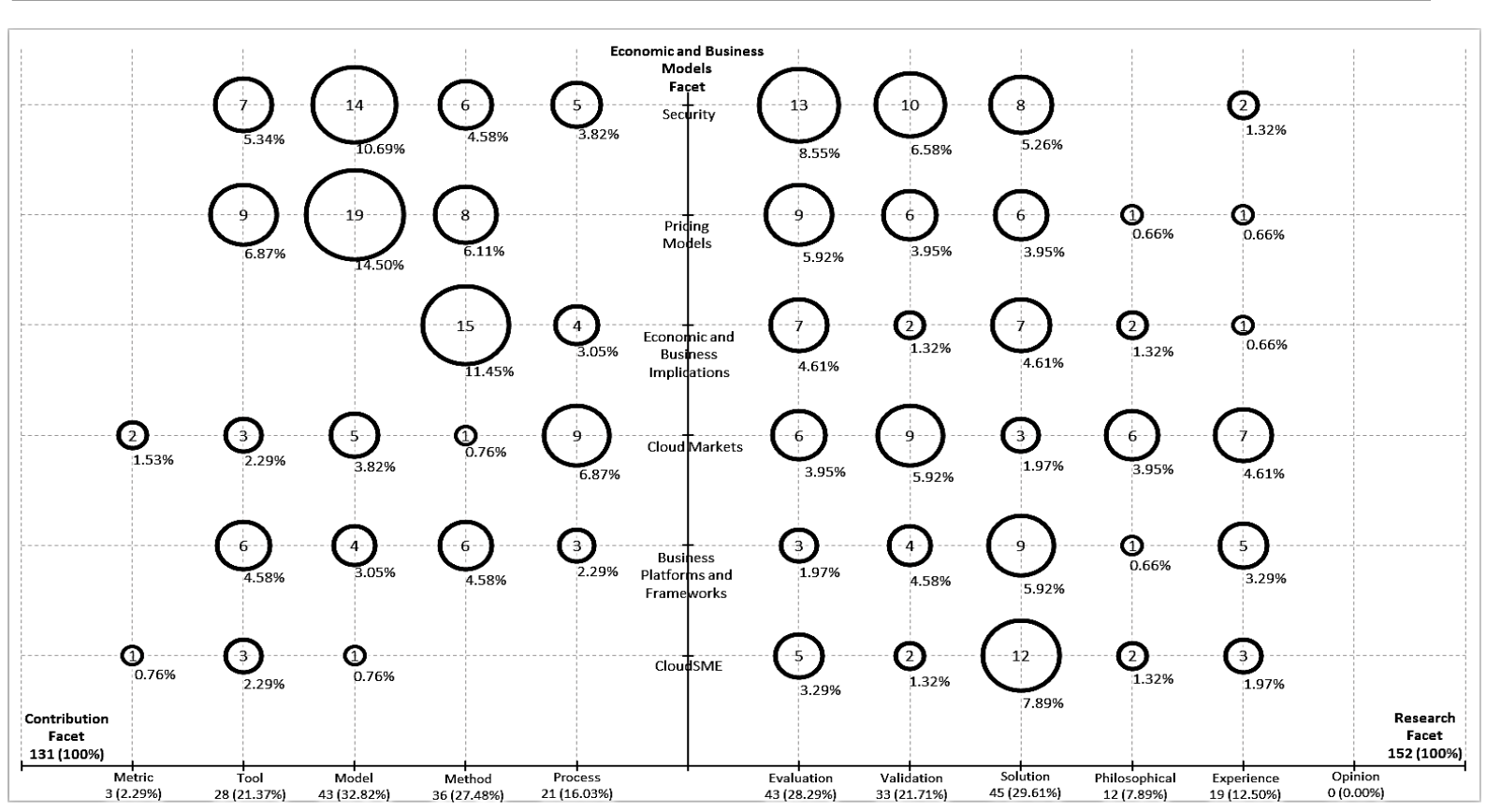

Figure 4. A systematic map on economic and business models of cloud services

\section{CONCLUSION}

Cloud computing, is a pay-per-use computing paradigm is continuously generating interest amongst organizations and individuals alike; particularly because it offers an avenue for cost optimization. Cloud services providers and customers will always want to optimize cost; hence, the need for research works which focuses on the economic and business models of Cloud services. There are large number of publication on this area, spanning various topics, a few of which include security and pricing models, Cloud SMEs, economic tools etc. Unfortunately, research work are not evenly distributed across these topics, as some area were more emphasized than others. Work on metric affecting pricing models, economic and business frameworks, methods and processes of Cloud SMEs for instance were few or non-existent, while those on model for security, Cloud markets, business models and frameworks were numerous. The systematic mapping study carried out in this paper offers a visual map showing at a glance, areas of higher frequencies of publication and those where there were shortage of papers. These shortages represent gaps in literature where future researchers can focus on. The map indicated areas where there were less emphasis in terms of economic and business models of Cloud services in terms of facets of the study. Contribution to knowledge has been realized by the gaps identified in several aspects of the study. Further research could also conducted to resolve contradictions and validate reslts. In summary, this study created a systematic map of economic and business models of Cloud services that could be beneficial to the cloud community. This study would help researchers discover research gaps in economic and business models of Cloud services thereby improving research options.

\section{ACKNOWLEDGEMENTS}

We would like to thank Covenant University Nigeria through the Centre for Research, Innovation and Discovery (CUCRID) for supporting this work.

\section{REFERENCES}

[1] R. Buyya, et al., "Cloud Computing Principles and Paradigms," John Wiley and Son, New Jersey, 2011, pp. 4-5.

[2] P. Mell, et al., "The NIST Definition of Cloud Computing", NIST Special Publication, 800-145, 2011.

[3] I. Odun-Ayo, et al., "Cloud Trust Management - Issues and Developments", Lecture Notes in Engineering and Computer Science: Proceedings of The World Congress on Engineering and Computer Science, 23-24 October, 2018, San Francisco, USA, pp. 369-374.

[4] I. Odun-Ayo, et al., "Cloud Management Optimization - Issues and Developments", Lecture Notes in Engineering and Computer Science: Proceedings of The World Congress on Engineering and Computer Science, 23-24 October, 2018, San Francisco, USA, pp. 357 
[5] T. Abayomi-Zannu, et al., "Cloud Identity Management - A Critical Analysis", Lecture Notes in Engineering and Computer Science: Proceedings of the International MultiConference of Engineers and Computer Scientists 2019 IMECS 2019, March 13-15, 2019, Hong Kong, pp. 170-175

[6] A. Al-Roomi, et al., "Cloud Computing Pricing Model: A Survey," International Journal of Grid and Distributed Computing. vol. 6, no. 5, pp. 93-106, 2013.

[7] P. Samimi, et al., "Review of Pricing Models for Grid and Cloud Computing," Computers \& Informatics (ISCI), 2011 IEEE Symposium on. IEEE, 2011.

[8] O. Dimitriu, et al., "Cloud Accounting: A New Business Model in a Challenging Context," Procedia Economic and Finance, 32, pp. 665-671, 2015.

[9] S. Labes, et al., "Common Patterns of Cloud Business Models," In proceeding of the 19th Americans Conference on Information Systems, Chicago, 2013.

[10] M. K. Mohan Murthy, et al., "Profit Driven Decision Assist System to Select Efficient IaaS Providers", International Journal of Electrical and Computer Engineering, vol.8, no.6, pp. 4398 4411, 2018

[11] I., Fitri Maya Puspita, et al., "Analysis Model in the Cloud Optimization Consumption in Pricing the Internet Bandwidth", International Journal of Electrical and Computer Engineering, vol.8, no.6, pp. 4391-4397, 2018

[12] S. Manikam, et al., "Business intelligence addressing service quality for big data analytics in public sector", Indonesian Journal of Electrical Engineering and Computer Science, vol. 16, no. 1, pp. 491-499, 2019

[13] K. Petersen, et al., "Guidelines for conducting systematic mapping studies in software engineering: An update", Information and Software Technology, vol. 64, pp. 1-18, 2015.

[14] J. L. Barros-Justo, et al., "Systematic mapping protocol: the impact of using software patterns during requirements engineering activities in real-world settings," Cornell University Library, arXiv:1701.05747v1 [cs.SE], 2017.

[15] I. Odun-Ayo, et al., "A systematic mapping study of cloud policy languages and programming models", Journal of King Saud University - Computer and Information Sciences, https://doi.org/10.1016/j.jksuci.2019.05.003

[16] T. Kosar, et al., "Protocol of a systematic mapping study for domain-specific languages," Journal of Information and Software Technology, pp. 77-91, 2016.

[17] M. Souza, L. et al., "A systematic mapping study on game-related methods for software engineering education," Information and Software Technology Vol. 95, pp. 201-218, 2018.

[18] I. Odun-Ayo, et al., "Cloud Design and Deployment Models: A Systematic Mapping Study”. BMC Research Notes $12(1)$, pp. 436.

[19] A. Ahmad, et al., "A systematic mapping study of empirical studies on software cloud testing methods," In IEEE International Conference on Software Quality, Reliability and Security Companion, pp. 555-562, 2017.

[20] B.I. Ya'u, et al., "A systematic mapping study on cloud-based mobile application testing" Journal of Information and Communication Technology. 18(4), pp. 485-527. 2019

[21] P. Brereton et al., "Lessons from applying the systematic literature review process within the software engineering domain," Journal of Systems and Software, vol. 80, no. 4, pp. 571-583, 2007.

[22] B. Kitchenham, et al., "Systematic literature reviews in software engineering-a systematic literature review" Information and Software Technology, Vol. 51, no 1, pp. 7-15, 2009.

[23] T. Wahyuningrum, et al., "A Systematic Mapping Review of Software Quality Measurement: Research Trends, Model, and Method", International Journal of Electrical and Computer Engineering. vol. 7, no. 5, pp. 2847-2854, 2017.

[24] R. Arokia Paul Rajan, "Service Request Scheduling based on Quantification Principle using Conjoint Analysis and Zscore in Cloud", International Journal of Electrical and Computer Engineering, vol. 8, no. 2, pp. 1238-1246, 2018

[25] S. Javadi-Moghaddam, et al., "Resource allocation in cloud computing using advanced imperialist competitive algorithm”, International Journal of Electrical and Computer Engineering, vol. 9, no. 4, pp. 3286-3297, 2019

[26] A.C. Muhammad, et al., "A Systematic Mapping Study of Software Architectures for Cloud Based System," Software System Section, 2014, IT University of Copenhagen.

[27] C. Wohlin, "Guidelines for snowballing in systematic literature studies and a replication in software engineering". Paper presented at the Proceedings of the 18th international conference on evaluation and assessment in software engineering. 2014.

[28] R. Wieringa et al., "Requirement Engineering Paper Classification and Evaluation Criteria, A Proposal and a Discussion”, In Requirement Engineering, vol. 11, no. 1, pp. 102-107, 2006.

\section{BIOGRAPHIES OF AUTHORS}

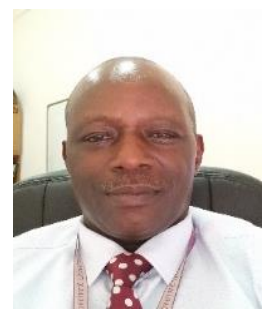

Isaac A. Odun-Ayo was born in Ilesha, Nigeria in 1962. He received the B.S, M.S and Ph.D degrees in Computer Science from the University of Benin, Benin City, Nigeria. Between 2010 and 2013 he was a faculty and Director Information and Communication Technology at the National Defence College, Abuja, Nigeria. He joined the faculty of Covenant University, Ota, Nigeria as a Senior Lecturer in October 2016. He is the author of one book and more than 40 journal and conference articles on Cloud Computing. His research interest include cloud computing, human resource management, e-governance and software engineering. Dr. Odun-Ayo is a recipient of the National Productivity Order of Merit Award, Nigeria for his contribution to computing. He is a member of the Nigeria Computer Society (NCS), Computer Professionals of Nigeria (CPN), International Association of Engineers (IAENG), Institute of Electrical and Electronics Engineers (IEEE) and Member Information Science Institute (ISI). 

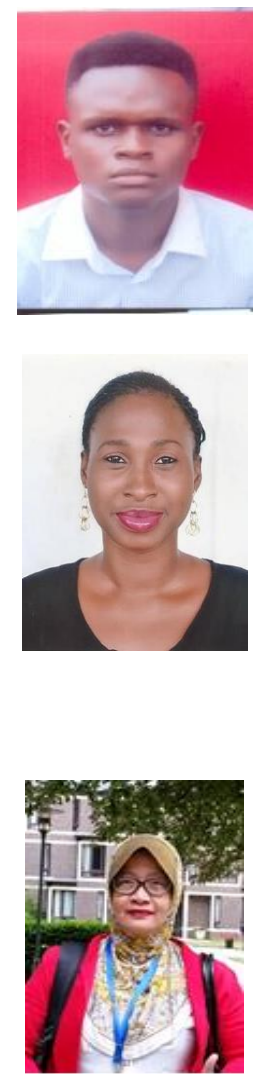

Toro-Abasi Williams is a research assistant and a postgraduate student at the Department of Computer and Information Sciences, Covenant University, Nigeria. He takes tutorials for several courses at the post-graduate level. He has a passion for academics and research in computer science. Williams has some publications in cloud computing His research interests include cloud computing, mobile computing, artificial intelligence and software engineering.

Olusola O. Abayomi-Alli received the B.Sc. degree in Electronics and Computer Engineering from Lagos State University, Lagos, Nigeria in 2008. She further obtained her Master's degree (M.Sc.) in Computer Science, Federal University of Agriculture, Abeokuta, Ogun State, Nigeria in 2015. She is currently pursuing her Ph.D. in Computer Engineering at the Covenant University, Ota. She is a member of several professional bodies such as the Nigerian Society of Engineers (NSE), Institute of Electrical and Electronics Engineers (NIEE), She has published in scholarly journals both National and International. She is a Lecturer II at the Department of Electrical and Information Engineering, College of Engineering, Covenant University, Ota, Ogun State. Her research interest includes areas such as: Computer security, pattern recognition, cloud computing, IoT and software engineering.

Jamaiah Yahaya is Associate Professor at Faculty of Information Science and Technology (FTSM), The National University of Malaysia (UKM) since July, 2011. Prior that she worked as a senior lecturer in School of Computing, Northern University of Malaysia (UUM) and a system analyst at University of Science Malaysia. Her bachelor degree was BSc in Computer Science and Mathematics from University of Wisconsin-La Crosse, USA (1986), MSc in Information System from University of Leeds, UK (1998), and PhD in Computer Science from The National University of Malaysia (UKM) (2007). Her PhD thesis was the development of software certification model and later, she continued her PhD research as a post-doctoral fellow in UKM (2008). Currently she is the head of PhD program in FTSM, UKM. Her research interests are software quality, software development and management, and software assessment and impact. She is an active researcher with more than 100 publications in international journals and proceedings for the last 5 years. 